\title{
DEBATES IN THE METHODOLOGY OF ECONOMICS \\ AND THE VALUE OF AN ENVIRONMENTAL \\ AMENITY
}

\author{
TOM KAUKO \\ Norwegian University of Science and Technology
}

\section{ABSTRACT}

The article discusses the extent to which the research methodology of heterodox economics is suited to the economic impact analysis of land use and real estate applications. Fulfilling the requirements of context-sensitivity, sub-optimality and pragmatism is argued to be relevant for increasing our conceptual understanding of property value in its multiple dimensions, and consequently for improving the process and outcome of environmental amenity valuation. Here three different issues need to be addressed: (1) the appropriate economic theory framework; (2) the particular geographic and institutional context; (3) the perceived costs vs. benefits of any impacts. Such an analysis is shown in a case study on water valuation in the Netherlands.

\section{INTRODUCTION}

Apparently little has been written on land use related economic impact assessment by those economists who attach the prefix heterodox ${ }^{I}$ or institutional to themselves. This is surprising, as it is intuitively natural for this group of experts to address issues related to normative and multi-dimensional considerations of the valuation of environmental goods, in the same way that communicative planners, management scientists and other experts in environmental assessment issues do. In this article I use an application on water value in the Netherlands to demonstrate the methodological possibilities of economic impact analysis, applying an in-between approach, loosely based on a classical institutional economics framework together with more behavioural aspects therein. The aim is to provide a rhetorical account on different scientific positions concerning the methodology of economic impact assessment with respect to environmental amenity.

Because of a failure to paint a realistic theoretical perspective on the nature of economic processes, the discipline of general economics is in great turmoil at the moment, and several directions for improvement have been proposed (see e.g. Lawson, 1997; Davis,

\footnotetext{
${ }^{1}$ Heterodox economics refers to an emerging methodological perspective where the aim is to utilise the plurality of approaches (evolutionary, institutional, behavioural, Austrian and so forth) to understand, explain and model economic behaviour and phenomena beyond neoclassical economics - the dominating perspective and mainstream approach.
} 
2006). It follows, therefore, that we should be able examine the same ideas in applied fields such as real estate and planning. ${ }^{2}$ Is this 'filtering of methodological innovations' a smooth and instant process - thanks to Internet - or do we need to look at the situation, like Thomas Kuhn, more pessimistically, as long as senior research managers with hegemonic affiliations function as gatekeepers in the applied science academia (cf. Garnett, 2005)? The way in which academic institutions evolve is, like other large hierarchical organisations, embedded in the prevailing power relations among the actors in the social network, and tends to be characterised by inertia (cf. Kersloot and Kauko, 2004).

The heterodox lines of reasoning, while only recently emergent, look for possibilities to cross-fertilise the discipline of economics using input from other disciplines such as sociology and human geography. While it is not a new observation that the neoclassical model has failed to deliver, it is fair to say that there has only recently begun to be a sufficient critical mass of academics who are taking the heterodox lines of thought seriously, and who deal with applied issues too. Furthermore, there is now the possibility of creating operational computerised models for prediction with neither economic equilibrium formalism, nor over-robustly designed top-down modelling underpinnings.

\section{THE NEOCLASSICAL MODEL AS A SPECIAL CASE OF THE HETERODOX MODEL}

Let us begin by assuming that the neoclassical model is categorically incorrect as a mode of scientific analysis. What then would be the alternative? Here we have the option of the cultural and institutional mode of social-economic analysis, and we need to accept that a relevant model has to be grounded in contextual knowledge and empirical evidence - this means adjusting the method rather than adjusting the data.

When elaborating this critique of the neoclassical model, at least three kinds of issues need to be raised: pluralism, equilibria and rationality. To what extent do we allow the objective to be examined from multiple different viewpoints? Under what circumstances, and at what level, does supply equal demand? What is the limit of an individual market participant's capacity to process information and evaluate alternative products in the market place? Below I look at some of these arguments using recent literature on economic methodology.

\footnotetext{
${ }^{2}$ The causality could also go the other way: practice adapts the tool first, before the theory catches up. Thus, theories and methodologies can develop in two different ways: either the science driven route, when a breakthrough in the 'mother-discipline' (general economics, for example) trickles down to the applied field; or the opposite route, when the practitioner simply discovers a short-cut to solving the problem and does not worry about whether the more conservative core of his/her research community accepts it, but only about being able to provide (at least) satisfactory results in terms of time- and cost-efficiency.
} 
Van Bouwel (2005) notes several potential motivations for pluralism: the reality itself; our capacity to understand the reality, the path and context specificity of phenomena; pragmatism (i.e. it all depends on the goals); and strategy (i.e. trying to legitimate one's own views). He then concludes that pluralism ought to engage in conversation between mainstream and heterodox approaches, and not follow the isolated road pawed by Tony Lawson and others. King (2004) advocates modified pluralism (that uses partial approaches, each of which can be appraised with respect to some criteria) ahead of pure pluralism (that entails a refusal to appraise methodologies). He does not approve of "selfproclaimed institutionalists" who use sophisticated mathematical tools derived from the biological sciences. He then makes a distinction between the healthy encouragement of contradictory ideas within the academy and the confusion in our own heads (i.e. postmodernism). Science has to be true: hence, the principle of consistency, according to King.

McCartney (2004) treats markets as "embedded in wider structures of values and institutions". Public regulations generate different outcomes in different countries, depending on their social structures. Liberalisation is thus neither a neutral nor deterministic process, but dependent on context: the particular social structure within which liberalisation occurs. Neoclassical theory forgets that. In a subsequent article, McCartney (2005) argues that the potential of game theory as an alternative way of modelling economic life has been neglected, while the main body of research has only focussed on showing game theory as a neoclassical variant. As such, game theory is broader than that, as it allows for situations with multiple equilibria. Game theory also does not assume independence between individual choices. He champions game theory as a relevant tool for economic analysis, although he laments the bias towards the methodological individualism of neoclassical economics. The issues explicitly recognised by game theory are realistic and preclude full rationality. Economic theory is here modelled to occur in a situation with interdependencies, in which case multiple equilibria outcomes can be modelled and single equilibrium only causes a special case.

Elsewhere, various behavioural and social scientists address similar concerns. Guerin (2003) makes a plea for intensive research methods to describe social, economic and cultural bases in behaviour analyses and rational choice models. This proposition draws on both traditional and post-modern approaches in order to make sense of the economic and social relationships that form the basis of how and when we can get things done. The idea here is "broadening social contingencies" so as to unveil consumer choice. According to Guerin, the issue is about how the organization of the social relationships within which people are embedded (family, migration, thinking, treatment of strangers and so forth) is influenced by the economics system. This may involve ritual uses. When the idea is to extend behaviour analysis into the real world of social life in general, and when analysing consumer preferences in particular, context and economic systems 
matter. Therefore, a new research agenda should be set using best approaches, recent discourses and observational tools, Guerin argues.

At a more applied level of analysis, Vatn (2004) discusses choices, preferences and rationality in environmental valuation. Using observations from valuation studies, he recognises the need to become more realistic and to understand the errors caused by illegitimate simplifications. While he sees possibilities for improving the systematic of neoclassical rationality, he notices the challenge of changing the assumptions of the rational choices in the model. He also notes the costliness of any piece of economic analysis, which is why we need to simplify the cognitive process. On the other hand, in the classic institutionalist formulation of rationality the concern is not only about cognitive, but also normative processes - the role of self matters but also protocols. We should then, according to Vatn, be working on classifications and social perspectives rather than with the utility determined by methodological individualism.

Like real estate, also land-use planning is preoccupied with the spatial and functional allocation of resources. Furthermore, in a supposedly converging institutional environment of planning and market regulation, the divide between the advocates of each camp, planning and real estate, is becoming narrower. Because of this connection, and the perhaps surprising possibility of opening up the neoclassical view, it is reasonable to assume that research into property valuation and the property market could benefit from incorporating some more explicit planning elements in order to cope with the dynamic and perhaps critical necessities involved in real estate research. (Cf. Tiesdell and Allmendinger, 2005)

Sophisticated evaluation methods are required in planning too. Sager (2003) compares two established ex-ante evaluation techniques in terms of their rationality: the goals achievement matrix (GAM, Hill, 1966) and the planning balance sheet (PBS, Lichfield, 1956). Whereas GAM is about the partial goals of the planning, the PBS is about the total welfare of all those affected. He concludes that both methods have their benefits and drawbacks. GAM distances itself from the unrealistic economic rationality concept, which is an advantage, but at the same time the technique is undermined by the possibility of manipulating the part evaluations. In PBS, on the other hand, the somewhat arbitrary outcome is obtained without showing the part-evaluations of the problem.

The discussion above has shown the complexity of the problem of defining rational behaviour, and the difficulty of finding a consensus perspective to build a platform for methodological advances. While the simpler, more general model of rationality always fits to some extent, in real life applications the exact problem formulation together with the feasibility considerations thereof are the key criteria for methodological selection (see also Kauko, 2004). 


\section{EVALUATING DIFFERENT THEORY PERSPECTIVES WITHIN REAL-ESTATE ECONOMICS}

In this field, most of our peers are eclectic when it comes to method and theory of housing market modelling and urban/land economics. At least institutionalism (even the old paradigm), evolutionarism, and behaviouralism are accepted approaches and perspectives for dissemination. Evolutionary dynamics is, at present, a prominent field in both planning and valuation applications alike, and the old idea of Leontjeff's inductive input-output analysis is viable too. Maybe there is also a strong bias to mainstream economics in this field, but apparently it is diminishing rapidly. Rational expectations and single equilibrium tools have been tried, and mostly they have failed to deliver.

Two aspects matter here: context, as argued by the older type of institutionalists, and non-rational and suboptimal decision-making and inertia as a consequence of internal or external factors, as argued by Austrians ${ }^{3}$, evolutionarists and behaviourists - to some extent also by the new institutionalists (who otherwise are really neoclassicists in disguise, cf. Adams et al., 2005; Pessali, 2006). Below I show the distinction between the two different basic economics perspectives (presentation adapted from Lawson, 1997; see also Weston, 2003). These two streams of thought have fundamentally different underpinnings in terms of both ontology (i.e. what the phenomenon is in reality) and epistemology (i.e. how the phenomenon is explained based on the knowledge of how it is constructed).

The neoclassical model

\section{CLOSED THEORY: THE ELEGANT WAY - ACCURACY GUARANTEED AFTER THE DATA IS FORCED TO FIT THE MODEL}

$$
\mathbf{x}=>\mathbf{y}
$$

- $\quad$ Determinism and mathematical solvability.

- $\quad$ The goodness of alternative models of explanation is decided on the basis of the explanatory power $\mathrm{R}^{2}$ or prediction accuracy.

\footnotetext{
${ }^{3}$ This comprises a cluster of theories of economic processes contributed by scholars with Austrian (or more precisely, Austro-Hungarian) origin. For general economics and economic geography, the two most influential Austrians are Joseph Schumpeter (1883-1950) and Friedrich (von) Hayek (1899-1992). However, Carl Menger (1840-1921), Eugene Böhm-Bawerk (1851-1914) and Frederick von Wieser (1851-1926) are mentioned by Canonne and Macdonald (2003) as having some relevance for property valuation.
} 
Open theory: the realistic way - conceptual soundness guaranteed, and therefore we do not need to force the data to fit the model, but rather adjust the method based on the expected outcome.

\section{The heterodox model}

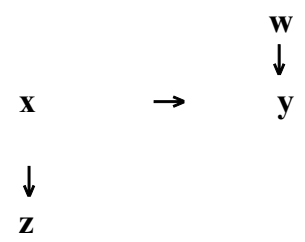

- No mathematical solvability, and accurate prediction is impossible.

- The goodness of alternative models of explanation is decided on the basis of how realistic the assumptions are (ontological reality).

\section{A MULTIDIMENSIONAL MODEL OF VALUE}

Real estate market dynamics and the locational component therein (locational value) comprise a multidimensional problem area. In some geographical-institutional contexts it may occur that housing consumers have widely diversified preferences on the one hand (bringing non-monetary benefits), while on the other hand the housing markets are very severely constrained (bringing costs related to scarcity value). This calls for a serious discussion on area assessment beyond the standard economic value assumptions. Firstly, we need to treat the problem with a systematic other than market equilibrium; secondly, we need to apply stated (and not just revealed) preference and choice methods in a partly qualitative context. Among some contributions that seem promising in broadening their intellectual horizons are works such as Gregory (2000) in the US, and Dent and Temple (1998) in the UK (cf. Ryan, 1998).

Accepting the proposition that the property value may consist of various incommensurable parts, how plausible is the notion of non-monetary benefits and value? Proponents of a liberalised property market equate the most profitable use of land with the most desirable one, thus overlooking social aspects of the market (Balchin and Kieve 1977, p. 112). However, this may lead to unsatisfactory land-use allocations, because not all interests are represented in the land market (Fisher and Krutilla, cited in Hanink and Kromley 1998). Hence the concept of 'market failure'. According to Balchin and Kieve (1977, p. 148-149) there are two basic problems in the valuation of costs and benefits: (1) to what extent will observed market prices reflect social valuation? (2) if markets do not exist, how are 'shadow prices' that reflect social values to be derived? 
It is possible to formalise the relationship between monetary and non-monetary values to some extent. Monetary values are based on a market equilibrium situation whereas the non-monetary values emerge from appreciation in a multidimensional and sentimental sense. Even classical economists such as Hurd (1903) asserted that the basis of residential values are essentially social rather than economic, and later Firey (1947) maintained that households became attached by forces of sentiment and symbolism to existing neighbourhoods (Maclennan 1982, p. 3-5). Recently, these issues have become even more important. Dent and Temple (1998) question the basis for economic valuation altogether. On the one hand fundamental economic changes and on the other hand evolving methodologies and culture or philosophy of the economics discipline forces the property research community to refine the approach to valuation. They suggest that land and property need to be described qualitatively in impact terms as well as quantitatively in reward terms whilst assessing the value of a property asset. Besides, it is a 'virtually unattainable' assumption to identify and quantify all the value characteristics.

The two mainstream theories at stake, the hedonic price theory and capitalization theory, link to the rational choice of the consumer and are useful tools, even in an operational sense. The partial prices describing a change in characteristics of the property basket of the dwelling can be utilised in two ways: either by calculating 'shadow prices' for changes in attributes or by calculating the value of a certain total package of property characteristics including location. Values other than economic can be studied independently and compared qualitatively amongst themselves, but not assessed in monetary terms. Besides this, they can be seen as a source for those values for which a price or "shadow price" can be approximated. Monetary values are mere reflections of some other values. It goes without saying that a monetary level evaluation is more credible, although a non-monetary level evaluation would be closer to the truth and less incorrect.

The monetary value is based on a neoclassical framework, and the non-monetary value on an institutional framework. The former is mainstream economics jargon; the latter is more of a planning concept, from the quality of environment literature. The difference between these two frameworks arises from the manner in which the essential nature of value is understood. In the neoclassical paradigm it can be measured as quantities, in the institutional paradigm only in qualitative terms. (Nevalainen et al. 1990, p. 48-52.) This implies that in the former paradigm a qualitative value can be measured as an economic value. Alternatively, it can be assessed as a non-economic, for example ecological value, in which case one has to switch from the neoclassical to the institutional way of thinking.

The last argument involved is how to decide about the extent to which one can successfully merge different perspectives into extended and in-between models. This is yet to be agreed upon among real estate and land use analysts (cf. Ball, 1998; Kauko, 2004; Needham and de Kam, 2004; Adams et al., 2005). Needham and de Kam (2004) discuss co-ordination mechanisms and transaction costs in land transactions, and assert that trust (embedded in rules) may be more important than price-clearing in land sales; 
thus, we need a better understanding of non-market institutions in all circumstances where non-price based allocation exists. Using a case study from the Netherlands they show how large housing associations have minimised transaction costs by forming trusts. Therefore, it is against the interest of the actors if the market becomes too transparent and price becomes the coordination mechanism. This is well-argued; when a competitive market is not likely to emerge, an alternative institution, decree, takes its place, which calls for attention in the assumptions of the analysis. However, the claim by Needham and de Kam (p. 2074) that a hybrid mainstream-institutional model is not possible to build - and that the ambition has to be limited to mere description and explanation without quantification - is less well-argued, because indeed various documentations show how operational extended or hybrid models can be developed to explain the exchange mechanism with input from heterodox economics, for example with the aid of state-of-the-art methods such as complexity theory (see Meen and Meen, 2003), or fuzzy logic (see Thériault et al. 2005).

\section{LAND USE CONSTRAINTS AND EXTERNALITIES}

In an ideal (equilibrium) world, all externalities could be quantified through the choices made and the prices paid by the housing consumers. However, the gap between a buyer's and a seller's valuation of the property does not disappear even if we manage to include all externalities in the model. If the seller has more power, or more information about the availability of alternatives, than the buyer - that is to say, in a setting characterised as oligopoly (or even monopoly) - this is bound to generate extra costs for the buyer. We are then dealing with the monopoly price concept - the other side of the same disequilibrium coin. Such an extra element in land price as a compensation for the loss of consumer surplus (i.e. the seller is not willing to sell his property at a value determined by market equilibrium) is indeed recognised in the land economics literature (Balchin and Kieve, 1977; Evans, 1983).

In congruence with the conceptualisation above, it is plausible that an environmental externality impact needs to be separated into two elements: one refers to a predominantly competitive market situation and a relatively unconstrained preference formation; the other refers to an imperfect market situation, where a supply or demand sided extra element emerges within the price formation. The relationship between the two elements depends on the prevailing physical, institutional or behavioural circumstances. Furthermore, since we deal with the interconnectivity of many factors (for example, distance to and quality of the amenity in question), isolating each factor is difficult.

On the demand side, the literature includes a debate between largely two kinds of perspectives or discourses: one, those who posit only the egotistic self-interest; two, those who, in addition, consider their being part of a community interest, thus the empathetic motive. On the supply side, too, the mechanisms and processes are not easily agreed upon. In some areas or regions it may be found that planning really has an active 
role in determining the long-term price levels. Namely, through the well-thought timing and volume of the land holdings the supply/demand balance, quality-levels and conflict situations might be either optimised, from the point of view of need, or abused, from the point of view of profit making. Weston (2002), for example, shows how house-builder behaviour is not dependent on macroeconomic factors in a mechanical sense, but that the picture is rather more discontinuous and 'patch-wise'- a process which depends on the context and is influenced by the behaviour of actors. This is not to deny that, spatially, price and new construction tend to overlap. Association is not the same as dependence, however. Thus the role of institutions as a determinant of property value can be seen when the market place is affected by normative impediments of various degree (cf. Adams et al., 2005).

\section{CASE: THE AMENITY VALUE OF WATER IN THE RANDSTAD HOLLAND}

When evaluating the amenity value of proximity to water, we can speculate that the preference for the sea over lakes, rivers and smaller bodies of water has to do with our evolution. The logic behind this preference structure might be that we came from the sea, as the evolutionary biologists claim and have therefore retained an unconscious affinity with it. Such affinity is however likely to vary between geographical and institutional context, and one must also be aware of possible dis-amenity impacts, mainly due to flooding. Below, the case of Randstad Holland region in the Netherlands is used to test the extent to which either generalisation or context-specificity holds when attempting to assess the impact of water-proximity. (See Goetgeluk et al., 2005, for a full documentation.)

This case is of importance social-culturally and because of its planning perspective. Firstly, water is being perceived as an amenity; it is, however, also perceived as a threat although recently the belief in technological solutions for water management (dykes and so forth) have reduced the negative effects. Secondly, given the planning paradigm in the Netherlands, potential locations for housing are restricted, which implies that overt behaviour, for instance expressed in hedonic models, does not reflect the preferences at all. Hence, the institutional, geographical differences have an impact on the validity of each economic perspective; that is to say, the mainstream neo-classical approach may not work well enough.

The following factors contribute to the validity of the results of the valuation:

- philosophical (whether an orthodox or heterodox theory model is more apt),

- geographical scale and institutional context of the valuation (these two different factors are treated as the same for simplicity's sake), and

- the psychological considerations caused by (dis)amenity factors (i.e. the positive vs. negative externality effects related to water). 
Following this logic, two results may emerge:

(1) The generalisations do not work. Hence, it means that we need a conceptual framework of the three factors above to determine which model we must use.

(2) The generalisations are useful, which implies that the context is less important than we thought.

The validity of our findings obtained from a given context and with a given set of assumptions is subject to the validity of the applied theories, methods and data sources, respectively. This topic is of great importance because the literature mainstream is implicitly 'coloured' by neoclassical thoughts, geographical and institutional context that allow neoclassical models to be valid, with a lack of real emphasis on validly assessing the hypothesised effects. This is not to say that the neoclassical perspective is incorrect, but rather, that it should be applied only under specific conditions. If this is not done, the results of the mainstream approaches in a 'non-mainstream' context will lead to poor predictions, which does not serve science and society.

Based on a systematic literature review, we suggested the following average magnitudes for the relative importance of the water amenity for the choice of residential location or as a determinant of property value (see Goetgeluk et al., 2005):

- revealed preference studies: for the sea $+10 \%$ price effect, for the lake and others no effect;

- stated preference studies: about $10 \%$ weight in relation to the total attractiveness.

The next task was to look for convincing evidence from specific institutional and geographical circumstances about all possible water impacts, when there are compared to, and evaluated against other kinds of environmental amenity impacts such as accessibility, social factors, physical factors and services. All these quality attributes were also treated as locational determinants of property value. For that purpose, we applied a semi-structured expert interviewing technique known as the analytical hierarchy process $(A H P)$ for eliciting the ranks for each attribute including the water impact. The AHP technique is based on the pair-wise preference comparison of elements (given attributes or alternatives), and results in a comparison matrix in which the relative importance of each element is determined as a ratio between 0 and 1 (Saaty, 1990; Zahedi, 1986). ${ }^{4}$

\footnotetext{
${ }^{4}$ Here it should be noted that the AHP itself and similar techniques of modern decision analysis are not to be considered an innovation in this context; in a strict positivist sense, such modelling has been carried by several property researchers (e.g. Ball and Srinivasan, 1994; Laakso et al., 1995, Bender et al., 1997, 1999, Din et al., 2001; cf. McLean and Mundy, 1998). It is rather that it can be used as a tool to generate evidence that can be compared with the general results assembled from the literature review.
} 
The basis for the AHP model structure was a set of attributes. The water proximity was defined as the net effect of the two different kinds of attributes. One was the amenity value: water quality, proximity and length of water frontage, view, size of water body $(+)$; the other was a risk of flooding with abatement costs (-). Six control variables were also included: accessibility, physical environment, social factors, services, municipality, and supply-side friction. The relative weights of each attribute for the location choices of the housing consumers, including water proximity, was then shown using the judgements of carefully selected expert respondents. ${ }^{5}$ In this way, various preferences profiles were elicited, and various dimensions of locational quality highlighted.

Our findings using the AHP (together with open interviews), suggested roughly a ten per cent weight of water proximity in relation to the total determinants of attractiveness. Furthermore, the open interviews suggested that this was mainly for the sea; for lakes and other bodies of water the effect was negligible as Dutch rivers, canals and marshlands were considered less spectacular (and sometimes even dis-amenities to the local residents) than the coastal dune-landscape.

While we had, at the outset, a presumption about differences to the mainstream literature (because of the special features of the context, as explained above), it turned out that no substantial difference was found! In the urban and nearby suburban segments in the Randstad we found out that the maximum $10 \%$ positive net effect holds regardless of how we measure it. Thus empirical evidence supports the literature findings from different contexts in this case too, which was surprising.

\section{CONCLUSIONS}

In the article certain methodological options and dilemmas were scrutinised, related to the comparability of various studies on environmental valuation. Although generalising is one of the goals of social scientific research, the level of generalisation should be useful for the valid description of the added value of a particular environmental amenity in other geographical and institutional settings. Because of partly political reasons, some geographical contexts, such as the Dutch Randstad, are examples of a scarcity of developable land and housing. This would thus largely invalidate the conclusions reached with a model, where the assumptions are set to fit Anglo-American conditions.

If the market is not in equilibrium, a measure of constraint needs to be added into the model. In such market disequilibrium the distribution of prices paid is not on a par with the distribution of locations in terms of their quality levels. When the assumption of

\footnotetext{
${ }^{5}$ During the year 2003 seventeen experts were interviewed from various organisations: each of them a stakeholder with a deep knowledge of the local housing market segments. These were managers of large development/building companies in the owner occupied sector (5 respondents), real estate agents and assessors (3 respondents), managers of housing corporations (5 respondents), consumer stakeholders (2 respondents), and government planning officers and researchers (2 respondents).
} 
equilibrium is relaxed, so as to allow for suboptimal housing market behaviour, the prices will arise as an outcome of either the seller or the buyer having to operate at a market place of limited choices. The key to the analysis is the perceived locational quality (or utility), when related to paid prices at the same location.

However, what if the generalisations and the empirical results were in the same range? Can we apply these generalisations without hesitation? The answer is 'no'; the AHP type of methods need some involvement beyond desk-research. Even if our research results correspond with the results of the literature review, we have to pay attention to the geographical-institutional constraints and to the net-effect of the positive and negative impacts. Besides these considerations, an issue of feasibility is involved. That is to say, it all depends on how much time and money we have at our disposal for investigating the issue of environmental amenity impact. Thus we have to conclude that yes, we can generalise a bit if we are exact about the spatial and institutional extent, and no, we also have to map the various specific factors involved.

To sum up the points raised in this paper, we need a more developed framework of economic value than that based on market solely. A recent article by Pardo-Guerra (2004) is appropriate here: instead of increasingly resembling a "a formal axiomatic dictum tailored with the patterns of physics and mathematics rather than with those of sociology and culture strudies", we need new methods that enable the incorporation of the non-monetary factors such as communication and ethics in order to expand economic theory. While this pertains to economics at large, we must conclude that the situation within the applied subdisciplines of land and real estate economics is none too different here.

\section{REFERENCES}

Adams, D., Dunse, N. and White, M. (2005) Conceptualising State-Market Relations in Land and Property: The Growth of Institutionalism - Extension or Challenge to Mainstream Economics? In D. Adams, C. Watkins and M. White (Eds): Planning, Public Policy \& Property Markets (RICS Research), pp. 37-55. Oxford: Blackwell Publishing.

Balchin, P. and Kieve, J. (1977) Urban Land Economics, London: Macmillan.

Ball, J. and Srinivasan, V.C. (1994) Using the Analytic Hierarchy Process in House Selection. Journal of Real Estate Finance and Economics, 9, pp. 69-85.

Ball, M. (1998) Institutions in British Property Research: A Review. Urban Studies, 35:9, pp. 1501-1517.

Bender A., Din A., Favarger P., Hoesli M. and Laakso J. (1997) An Analysis of Perceptions Concerning the Environmental Quality of Housing in Geneva. Urban Studies, Vol. 34, No. 3, 503-513. 
Bender A., Din A., Hoesli M. and Laakso J. (1999) Environmental quality perceptions of urban commercial real estate. Journal of Property Investment and Finance, Vol. 17, No. 3, 280-296.

Canonne, J. and Macdonald, R. (2003) Valuation without value theory: A North American “Appraisal”. Journal of Real Estate Practice and Education, 6(1), 113-162

Davis, J.B. (2006) The turn in economics: neoclassical dominance to mainstream pluralism? Journal of Institutional Economics, 2, pp. 1-20.

Dent, P. and Temple, M. (1998) Economic value - a methodological dilemma? The Cutting Edge 1998 -conference proceedings, ISBN 0-85406-922-4.

Din, A., Hoesli, M and Bender, A. (2001) Environmental Variables and Real Estate Prices. Urban Studies, Vol. 38, No. 11, 1989-2000.

Evans, A. W. (1983) The Determination of the Price of Land. Urban Studies, 20, pp. 119-129.

Garnett, R. F.:Jr. (2005) Whither heterodoxy?, post-autistic economics review, issue no. 34, $30 \quad$ October, article 1, pp. 2-21, http://www.paecon.net/PAEReview/issue34/Garnett34.htm

Goetgeluk, R., Kauko, T. and Priemus, H. (2005) Can Red Pay for Blue? Methods to Estimate the Added Value of Water in Residential Environments, Journal of Environmental Management and Planning, vol. 48, no. 1, January 2005, pp. 103-120.

Gregory R. (2000) Valuing Environmental Policy Options: A Case Study Comparison of Multiattribute and Contingent Valuation Survey Methods, Land Economics 76 (2), pp. 151-173.

Guerin, B. (2003) Putting a radical socialness into consumer behaviour analysis, Journal of Economic Psychology 24(5), October, pp. 697-718.

Hanink, D. M. amd Cromley, R. G. (1998) Land Use Allocation in the Absence of Complete Market Values. Journal of Regional Economics, 38, pp. 465-480.

Kauko, T. (2004) Infusing 'institution' and 'agency' into house price analysis, Urban Studies, Vol. 41, No. 8, July 2004, pp. 1507-1519.

Kersloot, J. and Kauko, T. (2004) Measurement of housing preferences - a comparison of research activity in the Netherlands and Finland. Nordic Journal of Surveying and Real Estate Research, vol. 1, no. 2, pp. 144-163.

King, J. E. (2004) Three Arguments for Pluralism in Economics, post-autistic economics review, issue no. 23, 5 January, article 2, http://www.btinternet.com/ pae news/review/issue23.htm 
Laakso, J., Bender, A., Din, A., Favarger, P. and Hoesli, M. (1995) An Analysis of Perceptions Concerning the Evironmental Quality of Residential Real Estate in Geneva, 1th IRES Conference, Stockholm 28 June -1 July, 1995

Lawson, T. (1997) Economics and reality. Routledge, London.

Maclennan, D. (1982) Housing economics. Longman, New York

McCartney, M. (2004) Liberalisation and Social Structure: The Case of Labour Intensive Export Growth in South Asia, post-autistic economics review, issue no. 23, 5 January, article 3, http://www.btinternet.com/ pae news/review/issue23.htm

McCartney, M. (2005) Game Theory: A refinement of an Alternative to Neo-classical economics, post-autistic economics review, issue no. 30, 21 March, article 2, http://www.btinternet.com/ p pae news/review/issue30.htm

McLean, D.G. and Mundy, B. (1998) The Addition of Contingent Valuation and Conjoint Analysis to the Required Body of Knowledge for the Estimation of Environmental Damages to Real Property. Journal of Real Estate Practice and Education, Vol. 1, No. 1, 1-19.

Meen, D. and Meen, G. (2003) Social Behaviour as a Basis for Modelling the Urban Housing Market: A Review. Urban Studies, 40(5-6), pp. 917-935.

Needham, Barrie and de Kam, George (2004) Understanding How Land is Exchanged: Co-ordination Mechanisms and Transaction Costs. Urban Studies, vol. 41, no. 10, September, pp. 2061-2076.

Nevalainen, R., Staffans, A. and Vuorela, P. (1990) Asumisen laadun arviointi ja tutkiminen. (Evaluating and studying the quality of housing, in Finnish.) YTK B 60, Helsinki.

Pardo-Guerra, J. P. (2004) When social physics becomes a social problem: economics, ethics and the new order, post-autistic economics review, issue no. 29, 6 December, article 1, http://www.btinternet.com/ pae news/review/issue29.htm

Pessali, H. F. (2006) The rhetoric of Oliver Williamson's transaction cost economics. Journal of Institutional Economics, 2, pp. 45-65.

Ryan, R. L. (1998) Local perceptions and values for a midwestern river corridor. Landscape and Urban Planning, 42, pp. 225-237.

Saaty, T.L. (1990) How to make a decision: The Analytic Hierarchy Process. European Journal of Operational Research 48, pp. 9-26.

Sager, T. (2003) Rationality types in Evaluation Techniques: The Planning Balance Sheet and the Goals Achievement Matrix, European Journal of Spatial Development, Jan.-no 2; http://www.nordregio.se/EJSD/ 
Small, G. and Sheehan, J. (2005) Valuing your Grandmother: Why customary title is incomparable to Western conceptions of property value. Paper presented at the Paper presented at the $11^{\text {th }}$ PRRES conference, Melbourne, Australia, 23-27 January.

Thériault, M., Des Rosiers, F. and Joerin, F. (2005) Modelling accessibility to urban services using fuzzy logic. Journal of Property Investment and Finance, 23:1, pp. 22-54.

Tiesdell, S. and Allmendinger, P. (2005) Planning Tools and Markets: Towards an Extended Conceptualisation. In D. Adams, C. Watkins and M. White (Eds): Planning, Public Policy \& Property Markets (RICS Research), pp. 56-76. Oxford: Blackwell Publishing.

van Bouwel, J. (2005) Towards a Framework for Pluralism in Economics, issue no. 30, $21 \mathrm{March}$, article 3, http://www.btinternet.com/ pae news/review/issue30.htm

Vatn, A. (2004), Environmental Valuation and Rationality, Land Economics, 80(1), February, pp. 1-18.

Weston, R. (2002) Towards a realist theory of market sector housing production in England. Paper presented at the European Network of Housing Research Conference Workshops, Vienna, Austria, 1-5 July.

Weston, R. (2003) Rhetoric: Methodology or Method? And Other Views from Heterodoxy. Comment on Focus article, Housing, Theory and Society, Vol. 20, No. 3, pp. 132-133.

Zahedi, F. (1986) The Analytic Hierarchy Process - A Survey of the Method and its Applications. Interfaces, 16(4) July-August, pp. 96-108. 